\title{
Características estruturais, produtivas e bromatológicas dos capins Tifton 85 e Jiggs fertilizados com alguns macronutrientes
}

\section{Structural, productive and bromatologic characteristes of Tifton 85 and Jiggs grasses fertilized with some macronutrients}

\author{
Adauton Vilela de Rezende ${ }^{1}$; Flávio Henrique Silveira Rabêlo ${ }^{2 *}$; \\ Carlos Henrique Silveira Rabelo ${ }^{3}$; Poliana Patrícia Lima ${ }^{4}$; Larissa de Ávila \\ Barbosa $^{5}$; Marcella de Carvalho Abud ${ }^{5}$; Flávia Romam Costa Souza ${ }^{6}$
}

\section{Resumo}

Objetivou-se avaliar o efeito da fertilização dos capins Tifton 85 e Jiggs com alguns macronutrientes sobre as características estruturais, produtivas e bromatológicas. Avaliaram-se duas forrageiras (Cynodon dactylon cv. Tifton 85 e $C$. dactylon cv. Jiggs) e cinco fontes de fertilizantes (três formulações NPK: 08-28-16, 30-00-20 e 20-10-10 e duas fontes de nitrogênio: ureia e super $\mathrm{N}$ ), em esquema fatorial $2 \mathrm{x}$ 5 , distribuídos em delineamento inteiramente casualizado, com quatro repetições. O plantio dos capins foi realizado sem adubação, simulando uma pastagem implantada em condições de baixa fertilidade natural. As maiores produções $(\mathrm{P}=0,009)$ e proporções de folhas $(\mathrm{P}<0,001)$ foram verificadas no capim-Tifton 85 , resultando em menor proporção de colmos quando comparado ao capim-Jiggs. As fontes de fertilizantes empregadas na adubação dos capins Tifton 85 e Jiggs alteraram o peso e a proporção de folhas e colmos, bem como a relação folha/colmo, número de perfilhos e produção de massa. Houve interação significativa entre os fatores de estudo (capim e fertilizante) quanto aos teores de MS ( $P=0,024)$, FDA $(P=0,012)$, hemicelulose $(P=0,007)$, DMS $(P=0,012)$, NDT $(P=0,012)$, ED $(\mathrm{P}=0,012)$ e $\mathrm{EM}(\mathrm{P}=0,012)$ das folhas, além do teor protéico $(\mathrm{P}=0,016)$ do colmo. De maneira geral, a aplicação do fertilizante 30-00-20 resultou em menor teor de FDA nas folhas do capim-Tifton 85 e maior digestibilidade da MS, com maior teor energético também, e o fornecimento de super $\mathrm{N}$ implicou em menor teor de FDA e maior digestibilidade da MS das folhas do capim-Jiggs. Considerando-se a planta inteira, o capim-Jiggs apresentou maior teor de $\operatorname{FDN}(P=0,017)$ em relação ao Tifton 85, entretanto, a concentração de FDA nesse capim foi menor $(\mathrm{P}<0,001)$ do que o Tifton 85 , o que implicou em maior digestibilidade da MS $(\mathrm{P}<0,001)$ e aporte energético $(\mathrm{P}<0,001)$. A aplicação do fertilizante super $\mathrm{N}$ diminuiu o teor de FDA $(\mathrm{P}=0,026)$ dos capins, principalmente do Jiggs, implicando em acréscimo na digestibilidade da MS $(P=0,026)$ e aporte energético $(P=0,026)$. Embora existam diferenças entre os dois capins, as características produtivas e nutricionais tornam essas forrageiras excelentes opções para a introdução em sistemas pecuários. O fornecimento das formulações NPK 20-10-10 e 08-28-16 é indicado para o cultivo dos capins Tifton 85 e Jiggs por aumentar a produção de massa e melhorar a qualidade nutricional das forrageiras.

Palavras-chave: Cynodon dactylon, fósforo, morfologia, nitrogênio, valor nutritivo

1 Prof., Instituto de Ciências Agrárias, Universidade José do Rosário Vellano, UNIFENAS, Alfenas, MG. E-mail: adauton. rezende@unifenas.br

2 Discente do Curso de Doutorado em Ciências, Centro de Energia Nuclear na Agricultura, Universidade de São Paulo, CENA/ USP, Piracicaba, SP. E-mail: flaviohsr.agro@usp.br

3 Discente do Curso de Doutorado em Zootecnia, Universidade Estadual Paulista "Júlio de Mesquita Filho", UNESP, Jaboticabal, SP. E-mail: carlos.zoo@hotmail.com

4 Discente do Curso de Mestrado em Fitotecnia, Universidade Federal de Lavras, UFLA, Lavras, MG. E-mail: polly-alp@hotmail.com

5 Engas Agras, UNIFENAS, Alfenas, MG. E-mail: larissabar@gmail.com; marcellabud@hotmail.com

6 Discente do Curso de Agronomia, UNIFENAS, Alfenas, MG. E-mail: flavia_romam@hotmail.com

Autor para correspondência 


\begin{abstract}
The aim this study was to evaluate the effect of fertilization of Tifton 85 and Jiggs grasses with some macronutrients on the structural, productive and bromatologic characteristics. Were evaluated two grasses (Cynodon dactylon cv. Tifton 85 and C. dactylon cv. Jiggs) and five sources of fertilizer (three formulations NPK: 08-28-16, 30-00-20 and 20-10-10, and two sources nitrogen: urea and super N) in a factorial scheme $2 \times 5$, distributed in a completely randomized design with four replications. The planting of grasses without fertilization was performed to simulate a pasture located in low natural fertility. The highest yields $(\mathrm{P}=0.009)$ and ratios of leaves $(\mathrm{P}<0.001)$ were observed in Tifton 85 grass, resulting in a lower proportion of stems when compared to Jiggs grass. The sources of fertilizers used changed the weight and the proportion of leaves and stems, as well as the leaf/stem ratio, number of tillers and mass production of Tifton 85 and Jiggs grasses. There was a significative interaction between the study factors (grass and fertilizer) for concentrations of DM $(\mathrm{P}=0.024)$, ADF $(\mathrm{P}=0.012)$, hemicellulose $(\mathrm{P}=0.007), \mathrm{DMD}(\mathrm{P}=0.012), \mathrm{TDN}(\mathrm{P}=0.012), \mathrm{DE}(\mathrm{p}=0.012)$ and $\mathrm{ME}(\mathrm{P}=0.012)$ leaves and the protein content $(\mathrm{p}=0.016)$ of the stem. In general, the application of 30-00-20 fertilizer resulted in lower ADF content in the leaves of Tifton 85 grass and higher DM, with higher energy content also, and providing super $\mathrm{N}$ implied lower ADF content and higher DM digestibility of Jiggs grass leaves. In the whole plant, the Jiggs grass had higher NDF $(\mathrm{P}=0.017)$ compared to Tifton 85 grass, however, the concentration of ADF that grass was lower $(\mathrm{P}<0.001)$ than Tifton 85 grass, which resulted in higher $\mathrm{DM}(\mathrm{P}<0.001)$ and energy intake $(\mathrm{P}<0.001)$. The application of super $\mathrm{N}$ decreased the ADF content $(\mathrm{P}=0.026)$ of grasses, mainly from Jiggs, implying an increase in the digestibility of DM $(\mathrm{P}=0.026)$ and energy content $(\mathrm{P}=0.026)$. Although there are differences between the two grasses, productive and nutritional characteristics make these excellent forage options for the introduction in livestock systems. The supply of NPK 20-10-10 and 08-28-16 formulation is suitable for the cultivation of Tifton 85 and Jiggs grasses by increasing mass production and improve the nutritional quality of the forage.

Key words: Cynodon dactylon, morphology, nitrogen, nutritional value, phosphorus
\end{abstract}

\section{Introdução}

Gramíneas do gênero Cynodon foram e têm sido introduzidas no Brasil pelas vantagens nutricionais, como elevado conteúdo protéico e fibra mais digestível comparada a outras gramíneas, além de possuir grande potencial produtivo, resposta à fertilização, adaptação a diferentes ambientes e flexibilidade de uso apresentadas nas condições dos Estados Unidos. Entretanto, para expressar todo o potencial, essas gramíneas forrageiras dependem de condições edafoclimáticas específicas, como maior precipitação e alta fertilidade do solo (BOTREL; NOVAES; ALVIM, 1998), justificando a avaliação da capacidade adaptativa e, consequentemente, do potencial forrageiro na região onde será estabelecido (ALVIM et al., 2003).

Entre os capins do gênero Cynodon introduzidos e cultivados no Brasil estão o Tifton 85 e o Jiggs. O Tifton 85 é um híbrido oriundo do cruzamento do cultivar Tifton 68 com uma introdução PI-290884, proveniente da África do Sul (BURTON; GATES;
HILL, 1993). Essa forrageira é perene, estolonífera, rizomatosa e possui elevado potencial de produção de forragem com qualidade (PEDREIRA, 2010). O Jiggs é uma variedade de grama bermuda (C. dactylon) e tem suas origens de certa forma desconhecidas. Acredita-se hoje que tenha sido desenvolvida por produtores americanos (BADE, 2000). Não há registros oficiais de sua introdução no Brasil, mas essa forrageira tem-se disseminado relativamente rápido, principalmente entre criadores de cavalos e bovinos de leite (PEDREIRA, 2010). O Jiggs é uma planta perene, de porte intermediário, que forma um dossel denso e de cor verde-clara. Possui folhas e estolões muito finos e poucos rizomas, que também não são muito grossos (MISLEVY, 2002).

A utilização de forrageiras desconhecidas ou pouco pesquisadas no País, como o capim-Jiggs, implica em produção animal abaixo do preconizado, pois a utilização de estratégias e tecnologias apropriadas para maximizar o desempenho animal nesse caso é mais limitada, o que pode 
ser ocasionado pelo manejo inadequado do solo e da planta (FAGUNDES et al., 2011). Esse fato determina a busca por estratégias que otimizem a produtividade e qualidade da forragem, de forma a aumentar a capacidade de suporte animal, uma vez que no Brasil as fases de cria, recria e terminação de animais ruminantes, especialmente bovinos, são realizadas em grande parte nas pastagens (SANTOS et al., 2009). Dessa forma, a utilização de fertilizantes é fator preponderante para aumentar a produção de massa e a qualidade das forragens (FAGUNDES et al., 2011; RABÊLO et al., 2012, 2013; RESENDE et al., 2013).

A fertilização fosfatada é fundamental para o estabelecimento das pastagens em solos tropicais, por meio do desenvolvimento do sistema radicular das gramíneas, melhor vigor de rebrota, aumento do perfilhamento, produção de massa e persistência da pastagem no ecossistema (GUSS; GOMIDE; NOVAIS, 1990; REZENDE et al., 2011). O fornecimento de nitrogênio proporciona incrementos lineares na produção de massa e altera significativamente a composição bromatológica da forrageira (BRÂNCIO et al., 2002). A adubação potássica também pode limitar o crescimento das pastagens pelos baixos teores disponíveis em solos tropicais e pelas funções fisiológicas que esse nutriente desempenha na planta (DECHEN; NACHTIGALL, 2007), bem como diminuir o potencial de resposta das forrageiras a adubação nitrogenada quando negligenciado.

Estudos mais detalhados de forrageiras introduzidas e cultivadas no Brasil são importantes por contribuir para o melhor entendimento do ecossistema das pastagens, gerando bases racionais para que o manejo da pastagem seja estabelecido (FAGUNDES et al., 2011). Portanto, objetivou-se avaliar o efeito da fertilização dos capins Tifton 85 e Jiggs com alguns macronutrientes sobre as características estruturais, produtivas e bromatológicas.

\section{Material e Métodos}

O experimento foi conduzido em vasos contendo $8 \mathrm{dm}^{3}$ de solo, provenientes da camada de $0-20 \mathrm{~cm}$ de um Latossolo Vermelho-Amarelo distrófico, textura argilosa, com a seguinte caracterização química (SILVA, 1999): $\mathrm{pH}$ em $\mathrm{H}_{2} \mathrm{O}=6,3$; P-Mehlich $=1 \mathrm{mg} \mathrm{dm}^{-3} ; \mathrm{K}^{+}=40 \mathrm{mg} \mathrm{dm}{ }^{-3} ; \mathrm{Ca}^{2+}=$ $4 \mathrm{cmol}_{\mathrm{c}} \mathrm{dm}^{-3} ; \mathrm{Mg}^{2+}=0,7 \mathrm{cmol}_{\mathrm{c}} \mathrm{dm}^{-3} ; \mathrm{Al}^{3+}=0 \mathrm{cmol}_{\mathrm{c}}$ $\mathrm{dm}^{-3} ; \mathrm{H}+\mathrm{Al}=1,5 \mathrm{cmol}_{\mathrm{c}} \mathrm{dm}^{-3}$; soma de bases (SB) $=4,9 \mathrm{cmol}_{\mathrm{c}} \mathrm{dm}^{-3}$; CTC potencial $=6,4 \mathrm{cmol}_{\mathrm{c}} \mathrm{dm}^{-}$ 3; saturação por bases $(\mathrm{V} \%)=76$; saturação por alumínio $(\mathrm{m} \%)=0$ e matéria orgânica (M.O.) $=15$ $\mathrm{g} \mathrm{kg}^{-1}$. De acordo com a Comissão de Fertilidade do Solo do Estado de Minas Gerais (RIBEIRO; GUIMARÃES; VENEGAS, 1999), os teores de $\mathrm{P}$ e $\mathrm{K}^{+}$no solo foram considerados muito baixo e médio, respectivamente.

O plantio dos capins foi realizado utilizando-se cinco mudas por vaso, sem adubação de plantio, simulando uma pastagem implantada em condições de baixa fertilidade natural. Decorridos 30 dias do plantio foi realizado o corte de uniformização dos capins, a $5 \mathrm{~cm}$ da superfície do solo, seguido da primeira adubação, conforme os tratamentos.

Avaliaram-se duas forrageiras (Cynodon dactylon cv. Tifton 85 e C. dactylon cv. Jiggs) e cinco fontes de fertilizantes (três formulações NPK: 08-28-16, 3000-20 e 20-10-10 e duas fontes de nitrogênio: ureia e super $\mathrm{N}$ ), em esquema fatorial 2 x 5 , distribuídos em delineamento inteiramente casualizado, com quatro repetições. Foram fornecidos $400 \mathrm{~kg} \mathrm{ha}^{-1}$ de $08-28$ $16,400 \mathrm{~kg} \mathrm{ha}^{-1}$ de 30-00-20, $500 \mathrm{~kg} \mathrm{ha}^{-1}$ de 20-10$10,500 \mathrm{~kg} \mathrm{ha}^{-1}$ de ureia $\left(45 \%\right.$ de N) e $400 \mathrm{~kg} \mathrm{ha}^{-1} \mathrm{de}$ super $\mathrm{N}(45 \%$ de $\mathrm{N})$, onde o custo de aquisição da tonelada do fertilizante foi adotado como parâmetro fixo e critério para estabelecer as doses utilizadas.

As aplicações dos fertilizantes foram realizadas após os cortes (30, 60, 90 e 120 dias após o plantio) e corresponderam ao fornecimento de $100 \mathrm{~kg} \mathrm{ha}^{-1}$ de 08-28-16, $100 \mathrm{~kg} \mathrm{ha}^{-1}$ de 30-00-20, $125 \mathrm{~kg} \mathrm{ha}^{-1}$ de $20-10-10,125 \mathrm{~kg} \mathrm{ha}^{-1}$ de ureia e $100 \mathrm{~kg} \mathrm{ha}^{-1} \mathrm{de}$ super $\mathrm{N}$ por corte. Os cortes subseqüentes ao de uniformização também foram realizados a $5 \mathrm{~cm}$ da superfície do solo. Na Figura 1 são apresentados os dados climáticos registrados durante o período experimental. 
Figura 1. Precipitação, temperatura média e umidade relativa do ar registrados durante o período experimental.

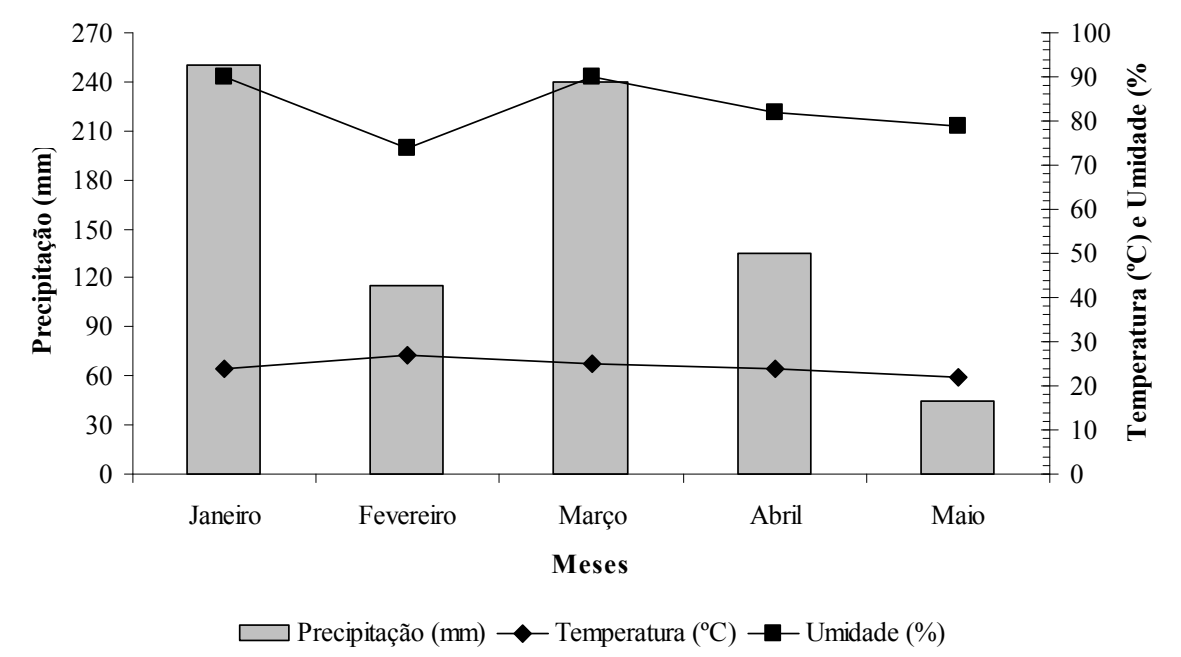

Fonte: Elaboração dos autores.

As avaliações estruturais, produtivas e bromatológicas dos capins foram realizadas nos cortes referentes a 60,90 e 120 dias após o plantio. A altura das plantas foi tomada da base da planta a ponta da última folha recém-expandida. A porcentagem e o peso de folhas e colmos foram definidos após as amostras permanecerem em estufa de circulação forçada de ar a $55^{\circ} \mathrm{C}$ por 72 horas. $\mathrm{O}$ número de perfilhos foi contabilizado antes da realização dos cortes. A produção de massa foi quantificada e extrapolada para um hectare, tomando-se por base o peso seco das plantas e a área superficial do vaso $\left(40 \mathrm{~cm}^{2}\right)$.

O material vegetal amostrado em cada corte foi alocado em estufa de ventilação forçada de ar a $55^{\circ} \mathrm{C}$ por 72 horas e moído em moinho do tipo Willey com peneira contendo crivos de $1 \mathrm{~mm}$ de abertura de malha. Após essa etapa foram realizadas as análises bromatológicas. Os teores de matéria seca (MS) e nitrogênio total (NT) foram determinados seguindo os métodos descritos pela AOAC (1990). A concentração de proteína bruta $(\mathrm{PB})$ foi obtida pelo produto da multiplicação do teor de NT e o fator 6,25. As determinações dos teores de fibra em detergente neutro (FDN) e fibra em detergente ácido (FDA) seguiram os métodos descritos por Goering e Van Soest (1970). A hemicelulose foi obtida pela diferença entre os teores de FDN e FDA. O teor de nutrientes digestíveis totais (NDT), energia digestível (ED), energia metabolizável (EM) e a digestibilidade aparente da matéria seca (DMS), foram calculados conforme reportado por Rodrigues (2009), em que estas variáveis não foram corrigidas para o nível de consumo, somente estimadas a partir dos parâmetros bromatológicos observados nas forrageiras:

$$
\begin{gathered}
\% \mathrm{NDT}=87,84-(0,7 \text { x \%FDA }) \\
\mathrm{ED}(\text { Mcal kg-1 de MS })=\% \text { NDT x } 0,04409 \\
\text { EM }(\text { Mcal kg-1 de MS })=\text { ED x } 0,82 \\
\% \text { DMS }=88,9-(0,779 \text { x \%FDA })
\end{gathered}
$$

Os dados apresentados nos resultados são valores médios obtidos dos três cortes avaliados em cada forrageira (60, 90 e 120 dias), uma vez que não houve avaliação do corte de uniformização (30 dias). Empregou-se a análise de variância com comparação de média pelo teste Scott-Knott $(p<0,05)$ por meio do programa estatístico SISVAR ${ }^{\circledR}$ (FERREIRA, 2011). 


\section{Resultados e Discussão}

$\mathrm{O}$ capim-Jiggs apresentou maior altura $(\mathrm{P}$ $=0,040)$ em relação ao capim-Tifton 85 , o que pode ser atribuído a morfologia específica de cada forrageira. Todavia, houve maior produção $(\mathrm{P}=0,009)$ e proporção de folhas $(\mathrm{P}<0,001)$ no capim-Tifton 85 , resultando em menor proporção de colmos $(\mathrm{P}<0,001)$ e maior relação folha/colmo $(\mathrm{P}<0,001)$ quando comparado ao capim-Jiggs (Tabela 1), corroborando Guimarães (2012), que relatou maior proporção de colmos no capim-Jiggs em comparação ao capim-Tifton 85 em condição de pré-pastejo. A relação folha/colmo é utilizada como parâmetro indicativo de qualidade nutricional, mas apresenta relevância variada de acordo com a espécie forrageira, sendo menor em espécies de colmo tenro e de menor lignificação (SBRISSIA; SILVA, 2001).

O capim-Tifton 85 apresentou maior perfilhamento $(\mathrm{P}=0,015)$ ao final do período experimental, com média de aproximadamente 90 perfilhos por vaso, porém, sem diferença quanto à produção de massa $(\mathrm{P}=0,329)$ em relação ao capim-Jiggs (Tabela 1). O perfilhamento da planta forrageira é uma resposta à fertilidade do solo associada à época, à freqüência e ao intervalo entre cortes (CORSI; NASCIMENTO JÚNIOR, 1994). Portanto, mesmo que os processos, mecanismos e princípios que determinam a produção forrageira sejam idênticos, a expressão das respostas assume valores distintos para cada espécie, visto que a plasticidade fenotípica, responsável pela amplitude das compensações entre esses processos e mecanismos é singular e específica (HODGSON; SILVA, 2002). Guimarães (2012) inferiu que o capim-Jiggs é bastante promissor nas condições do Estado de São Paulo por possuir características muito semelhantes ao capim-Tifton 85 quanto à produção de forragem e destacou a necessidade de avaliar as características bromatológicas dessa forrageira.

Maiores produções de folhas $(\mathrm{P}=0,001)$, colmos ( $\mathrm{P}<0,001)$, perfilhos $(\mathrm{P}<0,001)$ e massa seca $(\mathrm{P}<$
$0,001)$ ocorreram com o emprego dos fertilizantes 20-10-10 e 08-28-16 (Tabela 1), possivelmente devido à presença de fósforo nessas formulações, uma vez que o fertilizante 30-00-20 limitou as produções de folhas, colmos, perfilhos e massa seca em relação aos dois fertilizantes citados e o teor de fósforo no solo foi considerado muito baixo de acordo com a CFSEMG (RIBEIRO; GUIMARÃES; VENEGAS, 1999). O fósforo é fundamental para o estabelecimento e manutenção de pastagens em solos tropicais, uma vez que interfere diretamente no desenvolvimento do sistema radicular das gramíneas (GUSS; GOMIDE; NOVAIS, 1990). Portanto, é necessária avaliação criteriosa quanto ao tipo e dose de adubo fosfatado, pois o nutriente deve estar prontamente disponível e, em quantidade suficiente para a forrageira (REZENDE et al., 2011).

A maior proporção de folhas $(\mathrm{P}<0,001) \mathrm{e}$ relação folha/colmo $(P=0,006)$ verificadas com o uso de ureia e super $\mathrm{N}$ (Tabela 1), indicam que o nitrogênio altera as características morfológicas da planta, como tamanho de folhas e colmos, que alteram a relação folha/colmo (MARTUSCELLO et al., 2005).

Com relação à composição bromatológica dos capins, verificou-se maior teor de FDN $(\mathrm{P}<0,001)$ nas folhas do capim-Jiggs. Com isso, espera-se que esse capim seja menos digestível em relação ao Tifton 85 , já que normalmente este apresenta maior lignificação da fibra, como observado em outros estudos (OLIVEIRA et al., 2014a), resultando em menor digestibilidade da MS e valor nutricional do alimento. No entanto, considerando o teor de FDA como única variável para estimativa da digestibilidade da MS, o capim Jiggs apresentou maior digestibilidade $(\mathrm{P}<0,001)$, uma vez que possui menor teor de FDA $(\mathrm{P}<0,001$, Tabela 2$)$. Neste sentido, o arranjo tridimensional da fibra pode ter um grande impacto sobre a digestibilidade desta fração e do alimento como um todo (LEMPP, 2007). Gordin (2011) avaliou a digestibilidade in vitro da MS de gramíneas do gênero Cynodon e relatou coeficientes de digestibilidade de 77,03 e 
$71,43 \%$ na folha, 72,43 e $64,61 \%$ no colmo e 74,12 e $68,69 \%$ na planta inteira, para os capins Tifton 85 e Jiggs, respectivamente.

Somente os teores de PB das forrageiras foram alterados pela aplicação dos fertilizantes, verificando-se maiores teores $(\mathrm{P}<0,001)$ quando as fontes de maior concentração de nitrogênio foram empregadas (Tabela 2). Isso se deve provavelmente à maior presença de aminoácidos livres, que mantêm nitrogênio em sua estrutura, e de pequenos peptídeos no tecido da planta em resposta ao maior aporte de nitrogênio no solo (FREITAS et al., 2007).

Considerando que o teor de $\mathrm{PB}$ dos capins Tifton 85 e Jiggs verificados neste estudo não seriam limitantes ao consumo e desempenho animal (valores acima de 7,0\%), pode-se inferir que os teores de FDN encontrados nos dois capins poderiam ser limitantes em relação ao consumo, uma vez que ambos apresentaram valores superiores a 55,0\% (OLIVEIRA et al., 2014b; VAN SOEST, 1994; WHITEMAN, 1980). Como se sabe, há correlação negativa do teor de FDN com o consumo da forragem, por alterar a taxa de enchimento e passagem do alimento no sistema digestivo dos ruminantes (VAN SOEST, 1994). Entretanto, é preciso considerar que gramíneas do gênero Cynodon normalmente apresentam coeficientes de digestibilidade mais elevados quando comparados a outras forrageiras e, nesse sentido, o capim-Jiggs parece ter um arranjo estrutural da parede celular mais interessante para a nutrição animal em relação ao Tifton 85 .

Invariavelmente, as características bromatológicas apresentadas pelas folhas são mais desejáveis a nutrição animal quando comparada às apresentadas pelo colmo (Tabela 2), o que se deve à morfologia das gramíneas forrageiras, que apresentam tecidos foliares mais digestíveis e em maior proporção (WILSON, 1993). Com o avanço no grau de maturidade da forrageira, a incrustação dos tecidos com lignina é mais rápida nos colmos do que nas folhas, diminuindo a acessibilidade dos microrganismos ao conteúdo celular (WILSON, 1997). Todavia, o processo de pastejo e colheita de forragem pelos animais são controlados por inúmeros fatores, como a lotação animal, que implica em menor seletividade da forragem disponível em condições de superlotação.

Ainda em relação à composição bromatológica da folha e colmo dos capins, houve interação significativa entre os fatores de estudo (capim e fertilizante) quanto aos teores de MS $(\mathrm{P}=0,024)$, FDA $(\mathrm{P}=0,012)$, hemicelulose $(\mathrm{P}=0,007)$, DMS ( $\mathrm{P}$ $=0,012), \operatorname{NDT}(\mathrm{P}=0,012), \mathrm{ED}(\mathrm{P}=0,012)$ e $\mathrm{EM}(\mathrm{P}=$ $0,012)$ das folhas, além do teor protéico $(\mathrm{P}=0,016)$ do colmo (Tabela 3). De maneira geral, a aplicação do fertilizante 30-00-20 resultou em menor teor de FDA nas folhas do capim-Tifton 85 e maior digestibilidade da MS, com maior teor energético também, e o fornecimento de super $\mathrm{N}$ implicou em menor teor de FDA e maior digestibilidade da MS das folhas do capim-Jiggs. Comparando-se os dois capins dentro de cada fertilizante, somente a aplicação de 30-00-20 não proporcionou diferenças entre Tifton 85 e Jiggs, mas nos demais tratamentos foram observados menores teores de FDA no capimJiggs. Como resultado, a digestibilidade da MS e o teor energético foram maiores no capim-Jiggs com a aplicação de super N, 20-10-10 e 08-28-16. Em relação ao colmo, mesmo que o Tifton 85 seja mais protéico, a qualidade da fibra do colmo do capimJiggs (menor teor de FDA) implica sobremaneira em maior digestibilidade da MS, assim como maiores teores de NDT e energia. Como descrito por Van Soest (1994), a FDA é uma fração constituída principalmente de celulose e lignina, que se associa de forma negativa à digestibilidade dos alimentos. 


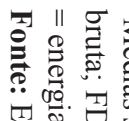

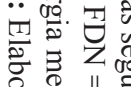$$
\text { (1) }
$$

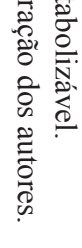
产.

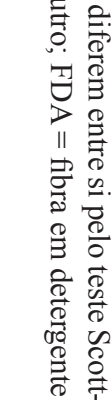

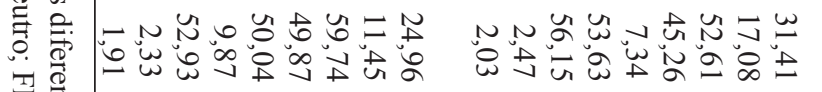

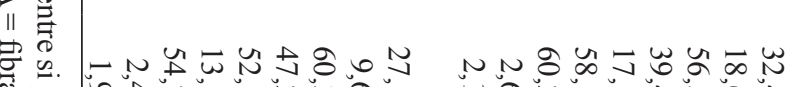

ठ

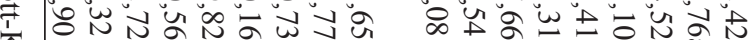

วั. ํํㅇ

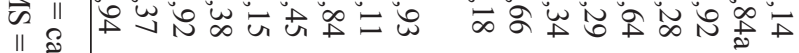

ㄴ.

象

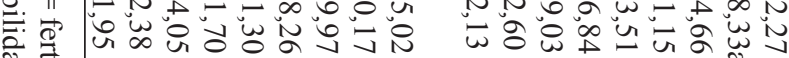

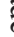

䒕

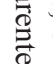

के

䓪

范

(1

总

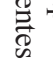

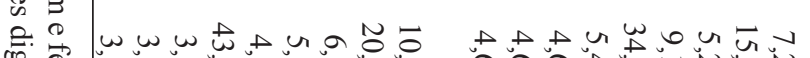

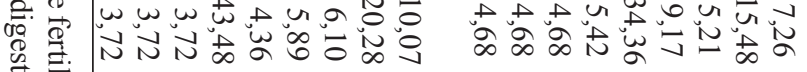

要.

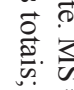

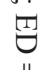

$\stackrel{9}{3}$ 宊. (10.0.

ڤ

产

药

- N U

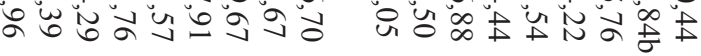

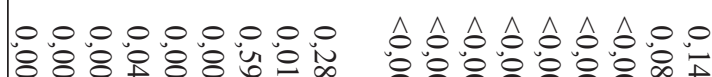

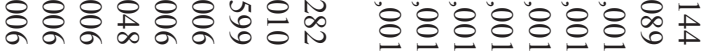

000000000000000000

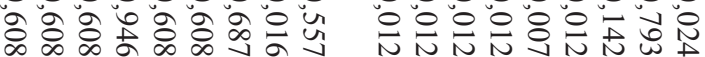

ำ

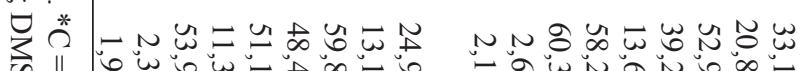

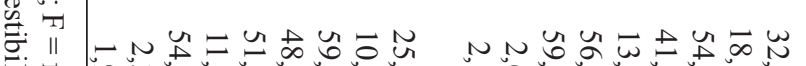

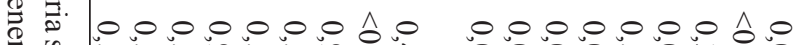

更

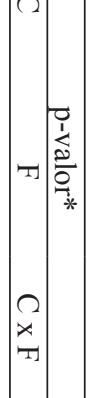

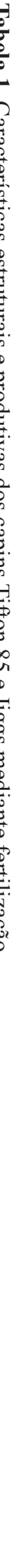


Tabela 3. Desdobramento da interação entre os fatores de estudo referentes às características bromatológicas e nutricionais da folha e colmo dos capins Tifton 85 e Jiggs mediante fertilização.

\begin{tabular}{|c|c|c|c|c|c|}
\hline Item & Ureia & Super N & $30-00-20$ & $20-10-10$ & $08-28-16$ \\
\hline \multicolumn{6}{|l|}{ Folha } \\
\hline \multicolumn{6}{|l|}{$\operatorname{MS}(\%)^{1}$} \\
\hline Tifton 85 & $33,23 \mathrm{aA}$ & $29,83 \mathrm{bB}$ & $33,03 \mathrm{aA}$ & $28,98 \mathrm{aB}$ & $29,42 \mathrm{aB}$ \\
\hline Jiggs & $33,20 \mathrm{aA}$ & $33,93 \mathrm{aA}$ & $29,99 \mathrm{aB}$ & $30,03 \mathrm{aB}$ & $32,52 \mathrm{aA}$ \\
\hline \multicolumn{6}{|l|}{ FDA $(\%)$} \\
\hline Tifton 85 & $45,34 \mathrm{aA}$ & $44,92 \mathrm{aA}$ & $39,75 \mathrm{aB}$ & $47,74 \mathrm{aA}$ & $48,60 \mathrm{aA}$ \\
\hline Jiggs & $40,88 \mathrm{bA}$ & $33,66 \mathrm{bB}$ & $42,56 \mathrm{aA}$ & $40,49 \mathrm{bA}$ & $39,85 \mathrm{bA}$ \\
\hline \multicolumn{6}{|c|}{ Hemicelulose (\%) } \\
\hline Tifton 85 & $7,38 \mathrm{bB}$ & $6,93 \mathrm{bB}$ & $13,42 \mathrm{aA}$ & $2,98 \mathrm{bB}$ & $5,99 \mathrm{bB}$ \\
\hline Jiggs & $15,46 \mathrm{aA}$ & $20,35 \mathrm{aA}$ & $13,60 \mathrm{aA}$ & $19,01 \mathrm{aA}$ & $17,09 \mathrm{aA}$ \\
\hline \multicolumn{6}{|l|}{ DMS (\%) } \\
\hline Tifton 85 & $53,58 \mathrm{aB}$ & $53,91 \mathrm{bB}$ & $57,93 \mathrm{aA}$ & $51,71 \mathrm{bB}$ & $51,04 \mathrm{bB}$ \\
\hline Jiggs & $57,06 \mathrm{aB}$ & $62,68 \mathrm{aA}$ & $55,75 \mathrm{aB}$ & $57,36 \mathrm{aB}$ & $57,86 \mathrm{aB}$ \\
\hline \multicolumn{6}{|l|}{ NDT $(\%)$} \\
\hline Tifton 85 & $56,10 \mathrm{aB}$ & $56,40 \mathrm{bB}$ & $60,01 \mathrm{aA}$ & $54,42 \mathrm{bB}$ & $53,82 \mathrm{bB}$ \\
\hline Jiggs & $59,23 \mathrm{aB}$ & $64,28 \mathrm{aA}$ & $58,05 \mathrm{aB}$ & $59,50 \mathrm{aB}$ & $59,95 \mathrm{aB}$ \\
\hline \multicolumn{6}{|c|}{$\mathrm{ED}\left(\mathrm{Mcal} \mathrm{kg}{ }^{-1} \mathrm{de} \mathrm{MS}^{-1}\right)$} \\
\hline Tifton 85 & $2,47 \mathrm{aB}$ & $2,49 \mathrm{bB}$ & $2,65 \mathrm{aA}$ & $2,40 \mathrm{bB}$ & $2,37 \mathrm{bB}$ \\
\hline Jiggs & $2,61 \mathrm{aB}$ & $2,83 \mathrm{aA}$ & $2,56 \mathrm{aB}$ & $2,62 \mathrm{aB}$ & $2,64 \mathrm{aB}$ \\
\hline \multicolumn{6}{|c|}{$\operatorname{EM}\left(\right.$ Mcal kg-1 de $\left.\mathrm{MS}^{-1}\right)$} \\
\hline Tifton 85 & $2,03 \mathrm{aB}$ & $2,04 \mathrm{bB}$ & $2,17 \mathrm{aA}$ & $1,97 \mathrm{bB}$ & $1,95 \mathrm{bB}$ \\
\hline Jiggs & $2,14 \mathrm{aB}$ & $2,32 \mathrm{aA}$ & $2,10 \mathrm{aB}$ & $2,15 \mathrm{aB}$ & $2,17 \mathrm{aB}$ \\
\hline \multicolumn{6}{|l|}{ Colmo } \\
\hline \multicolumn{6}{|l|}{ PB (\%) } \\
\hline Tifton 85 & $11,59 \mathrm{aA}$ & $12,95 \mathrm{aA}$ & $10,92 \mathrm{aA}$ & $13,24 \mathrm{aA}$ & $8,56 \mathrm{aB}$ \\
\hline Jiggs & $11,97 \mathrm{aA}$ & $13,28 \mathrm{aA}$ & $9,43 \mathrm{aB}$ & $6,61 \mathrm{bB}$ & $6,79 \mathrm{aB}$ \\
\hline
\end{tabular}

${ }^{1}$ Médias seguidas de letras diferentes minúsculas nas colunas e maiúsculas nas linhas diferem entre si pelo teste Scott-Knott. MS = matéria seca; $\mathrm{PB}=$ proteína bruta; FDA = fibra em detergente ácido; DMS = digestibilidade aparente da MS; NDT = nutrientes digestíveis totais; $\mathrm{ED}$ = energia digestível; $\mathrm{EM}$ = energia metabolizável.

Fonte: Elaboração dos autores.

Ao avaliar os capins desconsiderando os fracionamentos em folhas e colmos, constatou-se maior teor de FDN $(\mathrm{P}=0,017)$ no capim-Jiggs, mas a qualidade da fibra desse capim é melhor do que a apresentada pelo Tifton 85 (maior teor de FDA), o que resultou em maior digestibilidade da MS ( $\mathrm{P}<$ $0,001)$ e aporte energético $(\mathrm{P}<0,001)$ do mesmo (Tabela 4), corroborando os resultados obtidos nas folhas e colmos.

Em relação aos fertilizantes, constatou-se menor teor de FDA $(\mathrm{P}=0,026)$ nos capins devido à aplicação de super $\mathrm{N}$, resultando em maior digestibilidade da MS $(\mathrm{P}=0,026)$ e maior aporte energético $(\mathrm{P}=0,026)$ em relação às demais fontes utilizadas (Tabela 4). Esse fato pode estar associado à liberação mais lenta do nitrogênio fornecido por meio de super $\mathrm{N}$ quando comparado às outras fontes, mantendo um aporte mais constante desse nutriente no solo. Em condições normais de alimentação, a energia é o fator mais limitante ao desempenho de animais (VAN SOEST, 1994), e essa limitação pode ser eliminada ou potencialmente reduzida por meio da fertilização nitrogenada, fosfatada e potássica das pastagens, uma vez que a adubação promove melhorias na qualidade do alimento ofertado. 
Ao comparar produção de MS e teor de PB, notase que há uma relação direta e inversa entre esses parâmetros. Existe um antagonismo entre os teores de $\mathrm{PB}$ e produção de massa na mesma condição de fertilidade, acarretando na diluição do nitrogênio na planta quando ocorre aumento na produção de massa. A diminuição do nitrogênio no tecido foliar provoca em muitos casos aumento da absorção desse nutriente pela planta, porém nunca é suficiente para compensar a diluição. Portanto, nas mesmas condições de fertilidade, quanto maior a produção de massa menor será o teor de PB (CUNHA et al., 2001).

Tabela 4. Características bromatológicas e nutricionais dos capins Tifton 85 e Jiggs mediante fertilização.

\begin{tabular}{|c|c|c|c|c|c|c|c|c|c|c|c|}
\hline \multirow[b]{2}{*}{ Item } & \multicolumn{2}{|c|}{ Capim $^{1}$} & \multicolumn{5}{|c|}{ Fontes de fertilizantes $^{1}$} & \multirow[b]{2}{*}{$\mathrm{CV}(\%)$} & \multicolumn{3}{|c|}{ p-valor* } \\
\hline & $\begin{array}{l}\text { Tifton } \\
85\end{array}$ & Jiggs & Ureia & Super N & $30-00-20$ & $20-10-10$ & $08-28-16$ & & $\mathrm{C}$ & $\mathrm{F}$ & $\mathrm{C} \times \mathrm{F}$ \\
\hline MS (\%) & 28,40 & 29,24 & 29,20 & 28,94 & 28,57 & 29,05 & 28,34 & 5,60 & 0,366 & 0,530 & 0,154 \\
\hline PB (\%) & 14,26 & 14,11 & $15,76 \mathrm{a}$ & $16,97 \mathrm{a}$ & $14,25 \mathrm{a}$ & $13,21 b$ & $10,73 c$ & 15,52 & 0,821 & $<0,001$ & 0,203 \\
\hline FDN (\%) & 56,17 & 58,47 & 57,63 & 56,38 & 57,31 & 57,56 & 57,72 & 5,06 & 0,017 & 0,885 & 0,410 \\
\hline FDA $(\%)$ & 48,30 & 43,42 & $46,63 \mathrm{a}$ & $43,94 b$ & $46,54 \mathrm{a}$ & $46,12 \mathrm{a}$ & $46,07 \mathrm{a}$ & 3,79 & $<0,001$ & 0,026 & 0,539 \\
\hline $\begin{array}{c}\text { Hemicelulose } \\
(\%)\end{array}$ & 7,87 & 15,04 & 10,99 & 12,44 & 10,77 & 11,44 & 11,64 & 24,54 & $<0,001$ & 0,788 & 0,403 \\
\hline DMS (\%) & 51,27 & 55,07 & $52,56 \mathrm{~b}$ & $54,67 \mathrm{a}$ & $52,64 \mathrm{~b}$ & $52,97 \mathrm{~b}$ & $53,00 \mathrm{~b}$ & 2,18 & $<0,001$ & 0,026 & 0,540 \\
\hline NDT (\%) & 54,03 & 57,44 & $55,19 \mathrm{~b}$ & $57,08 \mathrm{a}$ & $55,26 \mathrm{~b}$ & $55,55 \mathrm{~b}$ & $55,58 \mathrm{~b}$ & 2,19 & $<0,001$ & 0,026 & 0,540 \\
\hline $\begin{array}{c}\mathrm{ED}(\mathrm{Mcal} \\
\left.\mathrm{kg}^{-1} \mathrm{de}^{\mathrm{MS}} \mathrm{S}^{-1}\right)\end{array}$ & 2,38 & 2,53 & $2,43 b$ & $2,51 \mathrm{a}$ & $2,43 b$ & $2,44 b$ & $2,45 b$ & 2,19 & $<0,001$ & 0,026 & 0,539 \\
\hline $\begin{array}{c}\mathrm{EM}(\mathrm{Mcal} \\
\left.\mathrm{kg}^{-1} \mathrm{de}^{\mathrm{MS}} \mathrm{S}^{-1}\right)\end{array}$ & 1,95 & 2,07 & $1,99 b$ & $2,06 \mathrm{a}$ & $1,99 \mathrm{~b}$ & $2,00 \mathrm{~b}$ & $2,00 \mathrm{~b}$ & 2,19 & $<0,001$ & 0,026 & 0,539 \\
\hline
\end{tabular}

${ }^{1}$ Médias seguidas de letras diferentes diferem entre si pelo teste $\mathrm{Scott}-\mathrm{Knott} .{ }^{*} \mathrm{C}=$ capim; $\mathrm{F}=$ fertilizante; $\mathrm{C} \mathrm{x} \mathrm{F}=$ interação entre capim e fertilizante. $\mathrm{MS}$ = matéria seca; $\mathrm{PB}=$ proteína bruta; FDN = fibra em detergente neutro; FDA = fibra em detergente ácido; $\mathrm{DMS}$ = digestibilidade aparente da MS; NDT = nutrientes digestíveis totais; $\mathrm{ED}=$ energia digestível; $\mathrm{EM}=$ energia metabolizável. Fonte: Elaboração dos autores.

\section{Conclusões}

Os capins Tifton 85 e Jiggs apresentam características produtivas semelhantes, mas o perfilhamento do capim-Tifton 85 é maior, o que pode aumentar a persistência dessa gramínea em sistemas de pastoreio intensivos. O capim-Jiggs por sua vez apresenta características nutricionais pouco mais desejáveis para a nutrição animal do que o capim-Tifton 85. Embora existam diferenças entre os dois capins, as características mencionadas tornam essas forrageiras excelentes opções para a introdução em sistemas pecuários.

O fornecimento das formulações NPK 20-1010 e 08-28-16 é indicado para o cultivo dos capins Tifton 85 e Jiggs por aumentar a produção de massa e melhorar a qualidade nutricional das forrageiras. Porém, é sabido que o fornecimento de formulações NPK não é suficiente para aumentar e/ou manter a eficiência produtiva e qualidade nutricional de gramíneas forrageiras por longos períodos de tempo quando os demais macro e micronutrientes não são fornecidos em quantidades adequadas.

\section{Referências}

OFFICIAL METHODS OF ANALYSIS - AOAC. Official methods of analysis of the association of official analytical chemists. $15^{\text {th }}$ ed. Washington: Association of Official Analytical Chemists, 1990. 406 p.

ALVIM, M. J.; BOTREL, M. A.; REZENDE, H.; XAVIER, D. F. Avaliação sob pastejo do potencial forrageiro de gramíneas do gênero Cynodon, sob dois 
níveis de nitrogênio e potássio. Revista Brasileira de Zootecnia, Viçosa, MG, v. 32, n. 1, p. 47-54, 2003.

BADE, D. H. Bermudagrass varieties: tifton 85, Jiggs, world feeder. Raleigh: North Carolina State University, 2000. Available at: <http://spfcic.okstate.edu/ proceedings/2000/extension/bade.pdf $>$. Accessed at: 09 dez. 2012.

BOTREL, M. A.; NOVAES, L. P.; ALVIM, M. J. Características forrageiras de algumas gramíneas tropicais. Juiz de Fora: EMBRAPA, 1998. 35 p. (Documentos, 66).

BRÂNCIO, P. A.; NASCIMENTO JUNIOR, D.; EUCLIDES, V. P. B.; REGAZZI, A. J.; ALMEIDA, R. G.; FONSECA, D. M.; BARBOSA, R. A. Avaliação de três cultivares de Panicum maximum Jacq. sob pastejo. Composição química e digestibilidade da forragem. Revista Brasileira de Zootecnia, Viçosa, MG, v. 31, n. 4, p. 1605-1613, 2002.

BURTON, G. W.; GATES, R. N.; HILL, G. M. Registration of "Tifton 85" bermudagrass. Crop Science, Madison, v. 33, n. 3, p. 644-645, 1993.

CORSI, M.; NASCIMENTO JÚNIOR, D. Princípios de fisiologia e morfologia de plantas forrageiras aplicados no manejo das pastagens. In: PEIXOTO, A. M.; MOURA, J. C.; DE FARIA, V. P. (Ed.). Pastagens: fundamentos da exploração racional. Piracicaba: FEALQ, 1994. p. 15-47.

CUNHA, M. K.; SIEWEREDT, L.; SILVEIRA JÚNIOR, P.; SIEWERDT, F. Doses de Nitrogênio e enxofre na produção e qualidade da forragem de campo natural de planossolo no Rio Grande do Sul. Revista Brasileira de Zootecnia, Viçosa, MG, v. 30, n. 3, p. 651-658, 2001.

DECHEN, A. R.; NACHTIGALL, G. R. Elementos requeridos à nutrição de plantas. In: NOVAIS, R. F.; VENEGAS, V. H. A.; BARROS, N. F.; FONTES, R. L. F.; CANTARUTTI, R. B.; NEVES, J. C. L. (Ed.). Fertilidade do solo. Viçosa: Sociedade Brasileira de Ciência do Solo/UFV, 2007. p. 92-132.

FAGUNDES, J. L.; MOREIRA, A. L.; FREITAS, A. W. P.; ZONTA, A.; HENRICH, R.; ROCHA, F. C.; BACKES, A. A.; VIEIRA, J. S. Capacidade de suporte de pastagens de capim-tifton 85 adubado com nitrogênio manejadas em lotação contínua com ovinos. Revista Brasileira de Zootecnia, Viçosa, MG, v. 40, n. 12, p. 2651-2657, 2011.

FERREIRA, D. F. Sisvar: a computer statistical analysis system. Ciência e Agrotecnologia, Lavras, v. 35, n. 6, p. 1039-1042, 2011.

FREITAS, K. R.; RUGGIERO, J. A.; NASCIMENTO, J. L.; HEINEMAM, A. B.; MACEDO, R. F.; NAVES, M. A. T.; OLIVEIRA, I. P. Avaliação da composição químico-bromatológica do capim mombaça (Panicum maximum jacq.) submetido a diferentes doses de nitrogênio. Bioscience Journal, Uberlândia, v. 23, n. 3, p. 1-10, 2007.

GOERING, H. K.; VAN SOEST, P. J. Forage fiber analysis (Apparatus, reagents, procedures and some applications). Washington, DC: USDA, 1970. 20 p. (Agricultural Handbook, 379).

GORDIN, C. L. Degradabilidade ruminal $e$ digestibilidade in vitro da matéria seca de gramíneas de Cynodon spp em quatro idades de rebrota. 2011. Dissertação (Mestrado em Zootecnia) - Universidade Federal da Grande Dourados, Dourados.

GUIMARÃES, M. S. Desempenho produtivo, análise de crescimento e características estruturais do dossel de dois capins do gênero Cynodon sob duas estratégias de pastejo intermitente. 2012. Dissertação (Mestrado em Ciência Animal) - Escola Superior de Agricultura Luiz de Queiroz, Piracicaba.

GUSS, A.; GOMIDE, J. A.; NOVAIS, R. F. Exigências de fósforo para estabelecimento de quatro leguminosas forrageiras em solos com distintas características físicoquímicas. Revista da Sociedade Brasileira de Zootecnia, Viçosa, v. 19, n. 5, p. 450-458, 1990.

HODGSON, J.; SILVA, S. C. da. Options in tropical pasture management. In: REUNIÃO ANUAL DA SOCIEDADE BRASILEIRA DE ZOOTECNIA, 39., 2002, Recife. Anais... Recife: Sociedade Brasileira de Zootecnia, 2002. p. 180-202.

LEMPP, B. Avanços metodológicos da microscopia na avaliação de alimentos. Revista Brasileira de Zootecnia, Viçosa, MG, v. 36, p. 315-329, 2007. Suplemento Especial.

MARTUSCELLO, J. A.; FONSECA, D. M.; NASCIMENTO JÚNIOR, D.; SANTOS, P. M.; RIBEIRO JÚNIOR, J. I.; CUNHA, D. N. F. V.; MOREIRA, L. M. Características morfogênicas e estruturais do capimxaraés submetido à adubação nitrogenada e desfolhação. Revista Brasileira de Zootecnia, Viçosa, MG, v. 34, n. 5, p. 1475-1482, 2005.

MISLEVY, P. Jiggs a potencial bermudagrass for central Florida. Ona: University of Florida, 2002. Available at: $\quad<\mathrm{http} / / /$ rcrec-ona.ifas.ufl.edu/pdf/publications/onareports/2002/July-2002.pdf>. Accessed at: 09 dez. 2012.

OLIVEIRA, E. R.; MONÇÃO, F. P.; GABRIEL,A. M. A.; GÓES, R. H. T. B.; LEMPP, B.; MOURA, L. V. Ruminal degradability of neutral detergent fiber of Cynodon spp. grasses at four regrowth ages. Acta Scientiarum. Animal Sciences, Maringá, v. 36, n. 2, p. 201-208, 2014a. 
OLIVEIRA, E. R.; MONÇÃO, F. P.; HOSTALÁCIO, A. N.; SANTOS, M. V.; FERNANDES, A. R. M.; GABRIEL, A. M. A.; MORAIS, M. G.; MOURA, L. V. Características de carcaça e de carne de cordeiros alimentados com dietas contendo diferentes genótipos de cynodon. Semina: Ciências Agrárias, Londrina, v. 35, n. 4, p. 2563-2578, 2014b. Suplemento 1.

PEDREIRA, C. G. S. Gênero Cynodon. In: FONSECA, D. M.; MARTUSCELLO, J.A. (Ed.). Plantas forrageiras. Viçosa: UFV, 2010. p. 78-130.

RABÊLO, F. H. S.; RABELO, C. H. S.; DUPAS, E.; NOGUEIRA, D. A.; REZENDE, A. V. Parâmetros agronômicos do sorgo em razão de estratégias de semeadura e adubação. Pesquisa Aplicada \& Agrotecnologia, Guarapuava, v. 5, n. 1, p. 47-66, 2012.

RABÊLO, F. H. S.; REZENDE, A. V.; RABELO, C. H. S.; AMORIM, F. A. Características agronômicas e bromatológicas do milho submetido a adubações com potássio na produção de silagem. Revista Ciência Agronômica, Fortaleza, v. 44, n. 3, p. 635-643, 2013.

RESENDE, M. L.; OLIVEIRA, J. A.; CASTRO, M. L. R.; RABÊLO, F. H. S.; RABELO, C. H. S. Yield parameters of maize crop in response to nitrogen fertilization, application of chemical fungicides and inoculation with Trichoderma harzianum. Pesquisa Aplicada \& Agrotecnologia, Guarapuava, v. 6, n. 2, p. 39-48, 2013.

REZENDE, A. V.; LIMA, J. F.; RABELO, C. H. S.; RABÊLO, F. H. S.; NOGUEIRA, D. A.; CARVALHO, M.; FARIA JÚNIOR, D. C. N. A.; BARBOSA, L. A. Características morfofisiológicas da Brachiaria brizantha $\mathrm{cv}$. Marandu em resposta à adubação fosfatada. Agrarian, Dourados, v. 4, n. 14, p. 335-343, 2011.
RIBEIRO, A. C.; GUIMARÃES, P. T. C.; VENEGAS, V. H. A. (Ed.). Recomendações para uso de corretivos e fertilizantes em Minas Gerais: $5^{\text {a }}$ aproximação. Viçosa: CFSEMG, 1999. 359 p.

RODRIGUES, R. C. Avaliação químico-bromatológica de alimentos produzidos em terras baixas para nutrição animal. Pelotas: EMBRAPA, 2009. 31 p. (Documentos, 270).

SANTOS, M. E. R.; FONSECA, D. M.; EUCLIDES, V. P. B.; RIBEIRO JÚNIOR, J. I.; NASCIMENTO JÚNIOR, D.; MOREIRA, L. M. Produção de bovinos em pastagens de capim-braquiária diferidas. Revista Brasileira de Zootecnia, Viçosa, MG, v. 38, n. 4, p. 635642, 2009.

SBRISSIA, A. F.; SILVA, S. C. da. O ecossistema de pastagens e a produção animal. In: REUNIÃO ANUAL DA SOCIEDADE BRASILEIRA DE ZOOTECNIA, 38., 2001, Piracicaba. Anais... Piracicaba: Sociedade Brasileira de Zootecnia, 2001. p. 731-754.

SILVA, F. C. Manual de análises químicas de solos, plantas e fertilizantes. Brasília: EMBRAPA, 1999. 370 p.

VAN SOEST, P. J. Nutritional ecology of the ruminant. $2^{\text {nd }}$ ed. Ithaca: Cornell University Press, 1994. 476 p.

WILSON, J. R. Forage intake from tropical pastures: chemical composition and anatomical traits. In: SIMPÓSIO INTERNACIONAL SOBRE PRODUÇÃO ANIMAL EM PASTEJO, 1., 1997. Viçosa. Anais... Viçosa: UFV, 1997. p. 173-208.

Organization of forage plant tissues. In: JUNG, H. G.; BUXTON, D. R.; HATFIELD, R. D.; RALPH, J. (Ed.). Forage cell wall structure and digestibility. Madson: American Society of Agronomy, 1993. p. 1-32.

WHITEMAN, P. C. Tropical pasture science. Oxford: Oxford University Press, 1980. 392 p. 
